\title{
Peer-teaching in the food chemistry laboratory: student-produced experiments, peer and audio feedback, and integration of employability skills
}

\author{
Julie L. DunNE ${ }^{a^{*}}$ \\ ${ }^{\text {a }}$ School of Food Science and Environmental Health, College of Science, Dublin Institute of Technology, Ireland \\ * Corresponding author \\ Julie.dunne@dit.ie \\ TEL: +35314024400
}

Received: 27 November 2013; Published online: 18 October 2014

\begin{abstract}
This paper describes the author's experience over the last several years of implementing an alternative Food Chemistry laboratory practical model for a group of third-year BSc Nutraceuticals students. The initial main objectives were to prepare students for the more independent final-year research project; to incorporate innovative approaches to feedback; and to integrate key employability skills into the curriculum. These were achieved through building the skills required to ultimately allow students working in groups to research, design and run a laboratory for their class. The first year of the project involved innovative approaches to feedback, including weekly feedback sessions, report checklists and audio feedback podcasts. Student evaluation after one year suggested the case group felt more prepared for final-year research projects and work placement owing to the redesign of the laboratory assessment. This, together with general positive feedback across several indicators, was proof of concept, and was a foundation for an improved model. The improvements related to the organisation and management of the project, but the same pedagogical approach has been retained. The second year saw the introduction of a more rigorous and easier to manage peer evaluation through use of the online Comprehensive Assessment for Team-Member Effectiveness (CATME) tool. The most recent revision has included a Project Wiki hosted on Blackboard ${ }^{\mathrm{TM}}$ to facilitate the organisation, communication, assessment and feedback of student-generated resources.

More recently, the final-year students who had participated in the peer-teaching Food Chemistry labs when in third year have been evaluated. This evaluation took place following their research projects, and suggests that the peer-teaching model better prepared them for these activities, compared to traditional laboratories.
\end{abstract}

Keywords: Food chemistry; Laboratory; Feedback; Peer-teaching; Group work; Self-directed learning, Peer assessment

\section{Introduction}

The aim of this project was to redesign the practical element of stage three Food Chemistry in a BSc Nutraceuticals degree programme, however the rationale for the redesign could also be transferred to almost any year-three science subject.
Year three does not receive as much attention in educational research as other years, particularly compared to the first year experience. Nonetheless, it is an important year, after which students must be prepared to enter semi-independent research in the form of fourth-year projects. Many students are ill-prepared for this leap from tra- 
ditional, recipe-style practical laboratories to research. Taylor and Geden (2008) describe fourthyear students who, up until final-year projects, believed 'most chemistry worked'. This is owing to the nature of traditional verification or expository laboratory teaching methods (Domin, 1999), where students follow a given procedure to obtain a pre-determined outcome. This allows students to manipulate equipment, learn standard techniques, collect and interpret data, and communicate the finding in a written report (Bennett \& O'Neale, 1999). While there is merit in this approach in achieving certain learning outcomes, the level of critical thinking required in performing the experiment, and the consequent deep learning achieved is low, and there is no opportunity for creativity or contextualisation (Mc Donnell, O'Connor, \& Seery, 2007). Additionally, co-operative learning, which requires students learning together with peer tutoring, is not facilitated by the environment of the traditional laboratory (Eilks, Markic, Baumer, \& Schanze, 2009). A more ideal approach integrates application of knowledge to solve problems, group work, and an opportunity to design experiments, including consideration of the safety aspects (Bennett, Seery, \& SovegjartoWigbers, 2009). This approach has been incorporated into chemistry education, both in secondyear mini-projects in this institute, as described by Mc Donnell et al. (2007), and elsewhere in other examples described therein.

Furthermore, the group work element is particularly important not only in relation to the socioconstructivist perspective on learning, but also because group work probably comes closer to any other single activity in preparing students for employment, and has been highlighted by the IBEC Results of Employer Survey, 2003 as an essential transferable skill. Indeed, the focus on development of key employability skills is increasing in the third level sector in general, with the needs of the employer as well as the graduate under consideration in the development of curricula. The importance of this in chemistry education is highlighted by the dedication of a Special Issue of Chemical Education Research and Practice focusing on the areas in the curriculum and the pedagogies which best support life-long learning (Bennett \& Overton, 2010). More broadly,
Yorke and Team (2004) describes employability in terms of management of self, others, information and task. This includes personal qualities such as self-awareness, self-confidence, independence, adapting to new challenges, initiative; core skills such as information retrieval, critical analysis, creativity, written and oral communication, including explaining; and process skills such as problem solving, prioritising, planning, and applying subject understanding. This publication describes a case study which aims to incorporate many of these aspects into the third year of a BSc Nutraceuticals degree, thus better preparing students both for final-year research projects and for subsequent entry to the workplace. The study involved innovative approaches to feedback, including weekly feedback sessions, report checklists and audio feedback podcasts.

\section{Methodology Overview and Implementation of Re-designed Food Chemistry Laboratories}

Food chemistry is broken into two modules, Food Chemistry I delivered in semester 1, and Food Chemistry II in semester 2. The practical element of the modules is worth $40 \%$ and comprises twelve 3 -hour sessions. In the years of implementation of this project the case study group consisted of about 22 students per module per year.

\section{$2.1 \quad$ Student group}

The student groups were selected based on their enrolment in TFBC3011 Food Chemistry I and TFBC3012 Food Chemistry II, Dublin Institute of Technology, Academic Years 2010/11 and 2011/12. These modules together cover Food Chemistry and Food Analysis. Further information on these modules can be found at www.dit.ie/catalogue.

\subsection{Food Chemistry I}

The task: Working in groups of 4 or 5 , students would take turns to assume the role of the instructor, and plan, organise, and run a labora- 
tory session for the rest of the class. The task involved the following duties:

- Health and Safety risk assessment;

- Researching the background of the experiment;

- Preparing a pre-practical presentation, including introduction to the practical, the method, and the safety;

- Liaising with the technician/lecturer to organize consumables/ equipment/ glassware;

- Giving the pre-practical presentation;

- With the assistance of the lecturer, aiding the smooth running of the lab;

- Giving post-practical session, including managing results.

This represented a significant change in student activity, compared to their other modules, both in their current year, and in their previous years. To account for this and to prevent undue stress, in the first semester the student groups were each allocated an experimental method known to operate successfully in the teaching laboratory in question.

\section{Assessment and Feedback for Food Chemistry I}

The breakdown of assessment for Food Chemistry I is presented in Table 1. As $50 \%$ of the laboratory assessment marks were being awarded for the peer teaching aspect of group work, some leniency in grading for the first and second groups was granted. This was based on the rationale that later groups would benefit and improve from observing and using their resources. For the case study group, the peer assessment required students to complete a form evaluating their group members on a scale of one to four for aspects specifically relating the their performance in the group work, and included: attended meetings, actively participated in activities, helped others, helped to keep to the task timeframe, had positive attitude and was respectful of others views, and contributed to the final presentation. More recently, the peer assessment has been managed using the online Comprehensive Assessment for TeamMember Effectiveness (CATME) tool available at https://engineering.purdue.edu/CATME. This provides a rating for each student in the group (usually between 0.8 for a less engaged student to 1.1 for a very engaged student), which was multiplied by the overall group score to provide individual marks for group work.

\section{Feedback}

Weekly feedback sessions: each group submitted a laboratory report in advance of this one hour session. All groups received a copy of each report. Each week a representative from each group participated in the feedback session. Peer review of each report was followed with expert feedback from the lecturer.

At the end of the module, the feedback from the weekly sessions was summarised and recorded by the lecturer, and made available to the students in the form of MP3 podcasts available on their Webcourses Virtual Learning Platform in advance of their final individual laboratory report.

Face-to-face feedback with the groups immediately after they ran the lab was also carried out, discussing their performance throughout the process. This feedback took the form of questioning to encourage reflection; for example asking the group how they felt the laboratory had gone, and what they would do differently in their planning and execution. This was followed by tutor feedback. This discussed their performance throughout the whole process, and included the manner in which they communicated with the lecturer and technician throughout, their prelaboratory planning, their student-generated resources, their ability to think ahead and to plan how to organise events taking place in the laboratory, the execution of their plans, and their ability to explain the theory and calculations to their peers, etc.

\section{$2.3 \quad$ Food Chemistry II}

The task: Once the students had successfully completed the module Food Chemistry I, and 
Table 1: Assessment of Food Chemistry I

\begin{tabular}{lll}
\hline Assessment & & Weighting \\
\hline \multirow{2}{*}{ Running the lab } & Overall planning and organisation, & $50 \%^{*}$ \\
& pre-practical presentation & \\
Laboratory reports & Weekly group laboratory reports (six in total) & $30 \%$ \\
& Final individual laboratory report & $20 \%$ \\
\hline Total & & $100 \%$ \\
\hline
\end{tabular}

${ }^{*}$ The group were awarded a mark which was weighted according to the results of the peer assessment

Table 2: Assessment of Food Chemistry II

\begin{tabular}{lll}
\hline Assessment & & Weighting \\
\hline \multirow{2}{*}{ Running the lab } & Use of literature, and effort towards experiment design, & $50 \%^{*}$ \\
& organising and running the lab & \\
\multirow{2}{*}{ Written reports } & A group poster presentation & $30 \%$ \\
& Final individual laboratory report & $20 \%$ \\
\hline Total & & $100 \%$ \\
\hline
\end{tabular}

${ }^{*}$ The group were awarded a mark which was weighted according to the results of the peer assessment

had developed the skills required to organise and run an allocated experiment, the process was repeated in semester 2 with Food Chemistry II. Here however, the emphasis was fundamentally different in that the students were charged with developing their own experiment. Groups were supported by the lecturer in their search of relevant literature, including the Association of Analytical Communities (AOAC) resources, standard food chemistry books, and appropriate journals. Students were also given a list of available equipment. In the first three weeks of the module students were guided towards choosing an appropriate experiment, and helped to transform methods from the literature into suitable experiments for a three hour laboratory. Much of this work was done during normal laboratory hours, but also required a considerable amount of selfdirected learning. Initially students brought literature, in areas they were interested in, into the laboratory. Then, together with the tutor, discussion on the appropriateness of the methods was held. These discussions included all feasibility aspects of the experiment: availability of chemicals and equipment; safety; and logistics of actually running the experiment in the timeframe. When a method deemed suitable on pa- per was agreed between student groups and the lecturer, students were given the opportunity to trial the experiment, to resolve any problems, and to know what to expect when running the lab for the whole class. As for Food Chemistry I, this required a risk assessment, and liaising with the technician to requisition consumables.

\section{Assessment and Feedback for Food Chemistry II}

The breakdown of assessment for Food Chemistry II is presented in Table 2. In this module, a group poster presentation was introduced as a means for students to record and present the whole process of designing the experiment, and also present the overall class results for their chosen experiment.

\section{Feedback}

Weekly face-to-face feedback on the process of using the literature, and choosing an appropriate experiment was provided to each group.

A feedback meeting was held with each group immediately after their experiment session, as per Food Chemistry I. 
The MP3 podcasts available on their Webcourses Virtual Learning Platform were again available for use for preparing the individual laboratory report.

A comprehensive report 'checklist' was provided, and had to be checked, signed and submitted along with the individual report. Included on the list to check was the requirement for peer second reading of the report. This Checklist is available in Appendix I.

The two-hour poster session involved peer feedback by all students on each poster, followed by lecturer feedback. Following this, groups were given the opportunity to re-submit the poster before a score was awarded.

\subsection{Recording of Podcast Feedback}

The feedback on writing laboratory reports which arose from Food Chemistry I weekly feedback sessions was summarized and scripted into the following sections:

Introductory note on purpose of feedback, General formatting and language, Aims and Objectives, Introduction section, Methodology section, Results section, Discussion session, Conclusion session.

The podcasts were between two and four minutes, and were recording using the free to download Audacity software (available at http://audacity.sourceforge.net/), and saved as MP3 files. These were uploaded directly to the Webcourses virtual learning platform, and could be listened directly using Windows Media Player, or downloaded to an MP3 player or Smartphone.

\subsection{Poster resources}

Students were directed to poster templates freely available on the internet (e.g. Harvard Medical School, and others) and also to a Study and Communication Skills Guide for the Chemical Sciences (Overton, Johnson, \& Scott, 2011)

\subsection{Pedagogical evaluation}

Pedagogical student evaluation was carried out at three stages during the course of this study.
Evaluations One and Two took place directly after the Food Chemistry I and II modules while the students were in third year (2010/11 and $2011 / 12$ ). This aimed to determine the students' thoughts about the model in general compared to a traditional laboratory, and also to determine the model's impact on their perception of preparedness for industrial placement and final-year projects. Evaluation Three took place a year later when they were in fourth year, following work placement and final-year research projects, and aimed to determine in hindsight the impact the Food Chemistry modules had (by comparison to traditional laboratories) in preparing them for these activities and determining how it may have affected their performance and developed their research and other generic skills.

Pedagogical evaluation took the form of anonymous evaluation sheets and requested students to disagree or agree with several questions using a four or five point Likert-type psychometric scale, and also allowed a comment to be recorded (Evaluation One and Two $\mathrm{N}=45$ repeated over two years. Evaluation Three $\mathrm{N}=21$ ). In addition, three independent academic facilitated focus groups have been hosted $(n=9,7,10)$ over the years. These were generally held after the anonymous evaluation data had been processed, and aimed to probe students' responses further. They took the format of more open-ended questions to encourage deeper discussion compared to the questionnaire. Focus group participants were selected to capture the opinions of each lab group where possible, and also to have a gender and age balance. The study was approved by the DIT Ethics Committee (DIT Research Ethics Committee approval number: 65/10) and all participants signed a consent form and were aware that the data would be used to further improve the teaching model, and could be used for publication purposes.

\section{Limitations of the study}

The study is bound by the normal limitations of self-reporting data for example, but not restricted to, subjectivity based on participants' feelings at the time of survey. An additional limitation of Evaluation Three is the students' ability to accurately remember the activities and assess- 
ments carried out in the previous year. In all of the evaluations, the study is limited to the relatively small student cohort. Therefore the data are useful only for the purpose of gauging general trends in student opinions.

The study is also limited by the common difficulty in determining whether activities and assessments in an educational environment have a direct impact on graduates' performance in the workplace or further research. According to the UK Commission for Employment and Skills (UKCES) - Employment Skills Project 'employability development is multi-factorial and context dependent, and may in many cases be long-term, any attempt made to evaluate a particular pedagogical approach will be limited, for example by the nature, volume and relevance of the evidence' (Pegg, Waldock, Hendy-Isaac, \& Lawton, 2012). The approach taken in this study is common to most reported local studies investigating employability skills development, whereby students are asked to self-assess their skills after trialling one or other pedagogical tactic. The UKCES report suggests such feedback is useful and should not be simply discounted; however it is limited in determining whether or not students have actually become more employable.

\section{Results and Discussion}

The results of student evaluation for Evaluation One and Two for third-year Food Chemistry I and II, respectively, are provided in Tables 3 and 4. The results for Evaluation Three following the cohort's fourth-year research projects and placement one year after Evaluations One and Two are presented in Table 5. In the discussion below, the results of the surveys are discussed together with the feedback from the focus group evaluations. The third-year results are discussed first, following by the fourth-year.

\subsection{Overview}

The practical element of a pair of associated Food Chemistry modules was redesigned to add value to the traditional laboratory experience, and to bridge the gap between traditional laboratory practicals ordinarily held in the first three years of undergraduate study, and the supervised semi-independent research normal in finalyear projects. The redesign retained the development of skills which traditional 'recipe-style' labs achieve, including allowing students to manipulate equipment and learn required laboratory techniques. Indeed many of the experiments, particularly in Food Chemistry I, were the same 'tried and tested' methods of a traditional lab. Importantly, according to Carnduff and Reid (2003), 'to change the experience, you don't need to change the experiment, just what you do with it'. This is beneficial from a resource perspective. Taylor and Geden (2008) took a similar approach in their re-invented second year laboratory, which aimed to provide an enquiry based experience for second year students ahead of capstone research projects. They made major changes to the previous laboratory manual and the pre-lab activities, but retained the actual experimental procedures to be followed to minimise resource implications.

However, for Food Chemistry II, the reform aimed to improve the student experience by providing students with the opportunity of putting the literature into context, in a supported setting, thus applying their knowledge to design their own experiment. This approach has been successful, with all students agreeing that choosing their own experiment had made the literature more relevant and meaningful, while almost all (overall 94\%) considered that designing their own experiment motivated them to engage with the literature. Students realised the difference between the methodology available in the literature, and how this is adapted for class experiments, with one claiming

you don't realise when you've always been given the method [in a lab manual], but when you go to the literature, it's like 'this is not in English!' and you have to look up three papers to get a single method.

This realisation will be critical for student's preparedness for final-year projects, where adapting the literature and experimental design will be the norm. During the course of the modules the students worked with the lecturer and technical staff to overcome problems in transforming

IJFS | October 2014 | Volume 3 pages 145-159 
Table 3: Student evaluation $(\%, \mathrm{n}=14)$ summary for Food Chemistry I

\begin{tabular}{|c|c|c|c|c|c|}
\hline Section & Question & $\begin{array}{l}\% \\
\text { Strongly } \\
\text { Agree }\end{array}$ & $\begin{array}{l}\% \\
\text { Agree }\end{array}$ & $\begin{array}{l}\% \\
\text { Disagree }\end{array}$ & $\begin{array}{l}\% \\
\text { Strongly } \\
\text { Disagree }\end{array}$ \\
\hline \multirow{6}{*}{ Running the lab } & Running a lab helped me to understand how to plan an experiment & 58 & 35 & 8 & 0 \\
\hline & Running a lab helped me to better appreciate Health and Safety issues & 31 & 38 & 27 & 4 \\
\hline & Running a lab was more challenging than recipe-style labs & 62 & 31 & 8 & 0 \\
\hline & Running a lab helped improve my employability skills such as team work, & 23 & 69 & 8 & 0 \\
\hline & organisation, communication and research & 12 & 42 & 4 & 4 \\
\hline & Running the lab helped to improve my presentation skills & & & & \\
\hline \multirow[t]{2}{*}{ Group Work } & $\begin{array}{l}\text { When I was part of the group running the lab I was more engaged and } \\
\text { motivated with the experiment than recipe-style labs }\end{array}$ & 48 & 32 & 20 & 0 \\
\hline & $\begin{array}{l}\text { In general, groups' ability to run the lab seemed to improve by gaining } \\
\text { from the experiences of previous groups }\end{array}$ & 54 & 42 & 4 & 0 \\
\hline \multirow{5}{*}{ Feedback } & Reading the reports of peers was a useful way to learn & 69 & 31 & 0 & 0 \\
\hline & The Feedback sessions were useful to attend & 76 & 24 & 0 & 0 \\
\hline & The whole group benefitted when a group member attended a Feedback session & 27 & 46 & 23 & 4 \\
\hline & The Audio Feedback on Webcourses was useful in preparing my final report & 60 & 32 & 8 & 0 \\
\hline & The Feedback (audio and sessions) will help with other module reports and assessments & 76 & 24 & 0 & 0 \\
\hline \multirow{2}{*}{ Assessment } & The marks allocation of the assessment is satisfactory & 44 & 44 & 12 & 0 \\
\hline & $\begin{array}{l}\text { The peer assessment was a good way to assess certain elements of group work e.g. } \\
\text { commitment and participation, contribution to organisation, contribution to presentation }\end{array}$ & 40 & 48 & 8 & 4 \\
\hline
\end{tabular}

Table 4: Student evaluation (\%, n=14) summary for Food Chemistry II

\begin{tabular}{|c|c|c|c|c|c|}
\hline Section & Question & $\begin{array}{l}\% \\
\text { Strongly } \\
\text { Agree }\end{array}$ & $\begin{array}{l}\% \\
\text { Agree }\end{array}$ & $\begin{array}{l}\% \\
\text { Disagree }\end{array}$ & $\begin{array}{l}\% \\
\text { Strongly } \\
\text { Disagree }\end{array}$ \\
\hline \multirow{7}{*}{$\begin{array}{l}\text { Choosing, designing } \\
\text { and running the lab }\end{array}$} & $\begin{array}{l}\text { Choosing our own experiment made the literature (journals, AOAC, books) } \\
\text { more relevant and meaningful }\end{array}$ & 72 & 28 & 0 & 0 \\
\hline & Choosing and designing our own experiment helped to motivate me to engage with the literature & 44 & 50 & 6 & 0 \\
\hline & $\begin{array}{l}\text { I was given enough time, support and relevant resources to allow me to choose, } \\
\text { evaluate and plan the lab to run for the class }\end{array}$ & 61 & 28 & 6 & 5 \\
\hline & It was very important to have a chance to try out the experiment ourselves first & 89 & 11 & 0 & 0 \\
\hline & Designing our own experiment for the class was challenging & 39 & 50 & 6 & 5 \\
\hline & Designing our own experiment for the class was too stressful for me & 6 & 11 & 61 & 22 \\
\hline & Food Chemistry I was a good preparation for this module & 78 & 22 & 0 & 0 \\
\hline \multirow{4}{*}{ Assessment } & The poster is a useful method of assessment & 33 & 44 & 22 & 0 \\
\hline & $\begin{array}{l}\text { The poster session including peer discussion of all the posters, and lecturer feedback, } \\
\text { has helped me if I have to do a poster in future }\end{array}$ & 83 & 17 & 0 & 0 \\
\hline & I am more comfortable with peer assessment this time around & 72 & 11 & 17 & 0 \\
\hline & I am satisfied with the overall assessment of the module & 67 & 33 & 0 & 0 \\
\hline \multirow{3}{*}{ Feedback } & I was given sufficient feedback throughout the module & 56 & 33 & 11 & 0 \\
\hline & I found the podcast feedback was a useful tool in preparing the individual lab report & 72 & 17 & 11 & 0 \\
\hline & The checklist was useful in preparing the final lab report & 78 & 17 & 6 & 0 \\
\hline \multirow{4}{*}{$\begin{array}{l}\text { Employability and } \\
\text { preparation for work placement } \\
\text { and final-year projects }\end{array}$} & $\begin{array}{l}\text { The module further helped improve my employability skills such as team work, organisation, } \\
\text { communication and research }\end{array}$ & 72 & 22 & 6 & 0 \\
\hline & I was more comfortable with group work this time around & 61 & 22 & 11 & 6 \\
\hline & I feel better prepared for the work placement due to the way the labs were run this year & 50 & 44 & 6 & 0 \\
\hline & I feel better prepared for my fourth-year project due to the way the labs were run this year & 65 & 29 & 0 & 6 \\
\hline
\end{tabular}


Table 5: Student evaluation $(\%, \mathrm{n}=14)$ following research projects and placement

\begin{tabular}{lccccc}
\hline $\begin{array}{l}\text { Post Project and } \\
\text { Placement Review }\end{array}$ & $\begin{array}{c}\text { Strongly } \\
\text { agree }\end{array}$ & Agree & Neutral & Disagree & $\begin{array}{c}\text { Strongly } \\
\text { Disagree }\end{array}$ \\
\hline Personal qualities & & & & & \\
Independence & 29 & 43 & 29 & 0 & 0 \\
Adapt to challenges & 36 & 43 & 21 & 0 & 0 \\
Initiative & 7 & 71 & 21 & 0 & 0 \\
Core Skills & 8 & 92 & 0 & 0 & 0 \\
Information Retrieval & 14 & 43 & 36 & 7 & 0 \\
Critical analysis of Information & 23 & 31 & 31 & 15 & 0 \\
Creativity & 7 & 50 & 36 & 7 & 0 \\
Oral Communication & 21 & 36 & 36 & 7 & 0 \\
Written communication & 21 & 64 & 14 & 0 & 0 \\
Team work & & & & & \\
Process Skills & 0 & 64 & 29 & 7 & 0 \\
Problem solving & 7 & 64 & 29 & 0 & 0 \\
Planning and organisation & 7 & 64 & 21 & 7 & 0 \\
Application of theory & & & & & \\
Impact of Food Chemistry Labs & 8 & 69 & 15 & 8 & 0 \\
Preparation for research project & 7 & 14 & 57 & 21 & 0 \\
Preparation for work placement & 7 & 57 & 36 & 0 & 0 \\
Preparation for career & & & &
\end{tabular}

the literature into a practical method suitable for use for the class as a whole. Most students (overall 89\%) felt they were given enough support and resources for this purpose, while all agreed that having a practice lab was critical. One student commented that 'if things go wrong, help is there, but you are not spoon-fed with the answer to the problem' while another believed that the best part of the module was 'learning how to be independent and stand on our own two feet in the lab'. Further preparedness for final-year projects included safety risk assessments, requisition of laboratory consumables and organising the lab in advance of running the class practical. Food Chemistry I was used to develop these skills in advance of Food Chemistry II, as it was believed that it would put undue stress on the students to learn these in tandem with experimental design. This approach seems to have been successful, with the majority of students believing that running the lab in the first semester helped them understand how to plan an experiment (overall $92 \%$ ) and appreciate the Health \& Safety issues (overall 65\%). This figure for Health \& Safety is however lower than expected. This is because an assessment in a Health \& Safety module had already dealt with laboratory safety, and therefore students felt they already understood these issues. Presumably if this assessment had not been carried out, this figure would be higher. Clearly, almost all students (overall 94\%) considered that, week after week, they were learning from the mistakes of previous groups. By semester two, all students believed that Food Chemistry I was a good preparation for the more challenging task of Food Chemistry II, with relatively few (overall $17 \%$ ) believing that designing their own experiment for the class was too stressful for them, with one commenting that 'it was a bit stressful, 5 on a scale of 1-10, more stressful than a traditional lab, but we gained a lot more from it' while another believed it to be 'a healthy stress'.

\subsection{Feedback}

Perhaps the most welcome aspect of these modules from the student perspective was the provision of varied, timely and relevant feedback, with frequent comments that it was the best feature of the modules. Petty (2006) discusses the meta- 
analyses of Hattie and Marzano, which claim that feedback is the single most powerful moderator to enhance student achievement. All students agreed that reflecting on their own reports, reading the reports of peers and discussing them with the lecturer at weekly feedback sessions was a useful way to learn. According to Higgins, Hartley, and Skelton (2001), rather than a list of assessment criteria, 'feedback may need to be more dialogical and ongoing. Discussion, clarification and negotiation between student and tutor can equip students with a better appreciation of what is expected of them'. One student remarked that 'you look at it [peer report] and think 'now I can see where I'm going wrong". This is consistent with the belief that effective assessment should allow students to become confident in making judgements about their own work, which ultimately takes account of the long term purpose of learning (Nicol, 2010). While many students (overall $73 \%$ ) did believe the whole group benefitted from a member attending a feedback session, there is room for improvement here. There was some communication breakdown with passing on the information from the session to the group as a whole. A possible solution to this, using a project Wiki, is discussed in the Current Improvements section below.

Particularly successful was the podcasted feedback. The use of technology in providing feedback is still under-utilised; however studies have reported positive results from audio feedback (Lunt \& Curran, 2010). According to Durbridge (1984) there are advantages of audio over printed media as comprehension is enhanced by the spoken word, adding clarity and meaning, and improving cognition. It is also consistent with appealing to different types of learner, as described by the VARK model by Fleming and Mills (1992). In other studies, students report that the most useful podcasts are those which give summaries and guidelines (Carvalho, Aguiar, \& Maciel, 2009). The students in this study mostly agree ( $89 \%$ overall) and believe it was useful in preparing their final report with one commenting 'It's such a simple thing, but it's so effective. I still use it for different subjects'. Together with the report checklist, which students also mostly believed (94\%) to be useful for this module's written report, there appears to be a form of 'feed-forward' or remediation feedback, which allows students' self-regulation, and to develop greater skills in self-evaluation (Hattie \& Timperley, 2007). All students agreed that the feedback provided would help with the assessments and reports in other modules, with one stating that 'I have put the checklist on my wall. If you follow it, you can't forget anything'.

\subsection{Assessment}

Overall the students were satisfied with the assessment of the modules under review. The poster assessment was generally well received (78\% overall) with students commenting that 'the poster made looking at someone else's group work more interesting than a set of ordinary lab reports'. Some students however felt that the poster may not be relevant as they may never have to produce a poster in the future. Students particularly welcomed the opportunity to re-submit the group poster following the poster session within two weeks. Despite it not being required, and complaints of a heavy workload in other modules, all groups opted to re-submit the poster. This is in line with best practice in assessment and feedback according to Nicol and Macfarlane-Dick (2004) and Black and Wiliam (1998), both suggesting that students should be able to engage in activities which help to close the gap between current and desired performance. Students felt 'looking at other's posters helped me to see where we went wrong, and what we did well and it was great that we got a chance to resubmit it' and 'it was good that she [the lecturer] didn't just say 'yeah, you should have put that in', but instead said 'right, off you go and make the changes'.

Peer assessment was introduced for several reasons: to evaluate teamwork performance which the tutor cannot see, to reduce the likelihood of students 'free-loading', and to help students identify which criteria are important in group work. While the students were mostly ( $88 \%$ overall) satisfied that the peer assessment was a good way of assessing certain teamwork-related contributions, from the author's perspective there were some issues. The first was purely from an assessment management and collation perspective. 
The paper-based system required distribution and collection of pages on a weekly basis, and the data entry was tedious. This also limited the scope and rigour of the peer review, which define the more academic concerns. Issues relating to both the management and rigour of the peer assessment have been overcome by the more recent introduction of the online Comprehensive Assessment for Team-Member Effectiveness (CATME) tool developed by Ohland et al. (2012). This tool has been developed based on a comprehensive review and knowledge of Peer Evaluation theory, psychology and instruments, which would be beyond the field of many scientific practitioners. The impressive research towards the development of CATME is readily available on the website (https://engineering.purdue.edu/CATME/ research.html). The five main areas shown to be important for assessing team work are:

- Contributing to the team's work;

- Interacting with teammates;

- Keeping the team on track;

- Expecting quality;

- Having relevant knowledge skills and abilities.

The tool is flexible, easy to use, and allows a tailored, behaviorally anchored rating scale survey to be developed. The rating scale describes behaviors that are typical of various levels of performance in each of the five categories. Once the students have been set up, they automatically receive an email link to the survey. Student raters select the category of behaviors that most closely matches the actual behavior of each student on their team (including themselves). The results from the peer evaluation provide the tutor with a rating for each student. In this case, the assessment marks outlined in Tables 1 and 2 were adjusted to provide each group with an overall mark for group work components, and the rating factor was multiplied by the group score to provide an individual mark for group work.

The CATME software also highlights 'exceptional conditions' which may indicate unfair or biased ratings, or team conflict. More information on this can be found on the CATME website.
The instrument has also been recently reviewed (Hrivnak, 2013).

\subsection{Preparedness for final-year projects and work placement}

Overall, almost all students (94\% overall) believed they were better prepared for final-year projects due to the way the modules were run, with one suggesting the experience was 'like a stepping stone towards final-year projects'. Furthermore, the majority of students believed that Food Chemistry I and II (overall $92 \%$ and $94 \%$ respectively) has increased their employability skills, including teamwork, organisation, communication and research, in agreement with Bennett and co-workers who note that the learning outcomes from non-traditional laboratories are transferable in nature, and can be applied to a wide range of activities beyond the immediate task (Bennett et al., 2009). Surprising, only about half the group ( $54 \%$ overall) thought that it had improved their presentation skills, but on further examination, this was because they either felt they were already good at presenting, or because they had not actually been part of the presenting team. In future, the latter could be improved by suggesting that all students must present at least a small part of the presentation. Interesting, one student commented that 'we looked at running the lab like it was a job' while another described how she 'talked about this module in my interview for work placement. It made me feel like more of a grown up person, not just a student'. Clearly, the students consider the experience to be more authentic and relevant to the workplace.

\subsection{Evaluation following final-year projects and placement}

Evaluation of the students who had recently completed their research projects suggests that $77 \%$ (with 15\% neutral) of them in hindsight felt that the peer teaching module better prepared them for their projects, compared to a traditional lab format.

While a small proportion remained neutral, no students disagreed that their Personal Qualities 
of Independence, Adapting to challenges, and Initiative had improved. Regarding their Process Skills of Problem solving, Planning \& organisation, and Application of theory again most felt they had better developed these skills in the Food Chemistry lab, with just a small number believing a traditional lab would have better developed these skills. Their specific learning has been captured by several similar comments throughout the evaluation forms and in the focus group, such as "We had to have everything ordered the week before. It taught us better planning and organising skills'. Focussing on their Core skills, all students felt their Information retrieval skills had improved. In the focus group, students explained 'this was the first lab we had to read papers for. You might have read some before for a bit of background for an introduction, but not for methods' and 'before we were always given the method but this time we had to find or adapt methodology. It took the fear out of not being given the method'. However, their feelings toward Critical analysis of the literature are mixed, with only $57 \%$ overall reporting these skills had developed and $36 \%$ remaining neutral. The focus group suggests this may be a combination of two factors. Firstly, they explained that many may not have understood what critical analysis of the literature meant. In all likelihood, this is part of the wider debate on critical thinking, which is considered poorly defined as a concept even by academics and also, because it is learned intuitively, is poorly explained to students throughout their education (Martin Davies, 2008). Secondly, some do not believe such a short and directed project can reveal enough about the literature to merit being overly critical. One student suggested ' $I$ think experience and time are the only way to develop this skill. If it [the reported methodology] messes up, you learn to be critical.' In terms of Oral Communication and Written communication, the feedback in the focus group was not in agreement with the evaluation figures (which were not entirely positive). Students in the focus group felt they were communicating all the time, within their group, with other peers and with the teacher. Comments relating more specifically to the benefit for their projects were also positive, such as 'the pre-lab presentation really helped with the final-year project presen- tation, especially with dealing with questions at the end of the presentation and thinking on the spot'. They also reinforced the sentiment of the third-year students towards the feedback they received on their reports, and how this benefitted them when they were writing their final-year thesis. It remains unclear why a higher number of students opted to remain neutral for these questions relating to communication.

An initially disappointing result was the low positive response in relation to the benefit in hindsight of the Food Chemistry lab in preparing the students for work placement. A significant number of students remained neutral on this (57\%) with the remaining students evenly split between agreeing and disagreeing that the modules better prepared them for placement. This is in contrast to the question relating to their overall preparedness for their career, to which most students (64\% overall) answered in agreement (and the others remained neutral, with none disagreeing). This was puzzling, but here the focus group exposed further insight on these results. Some students took a very literal understanding of the term 'preparation' and answered negatively if they did not carry out a laboratory based placement. Additionally, while further investigation is required, it appears that many of the placement activities involved very closely supervised work, with little requirement for initiative or self-direction on behalf of the student. One commented
those skills were needed on my place- ment, but not at a very high level. I would have liked if my placement was a bit more challenging. But maybe they won't give these challenges to place- ment students? It was more useful to see how an industry works rather than apply my skills.

While students became very familiar with the operation of the placement tasks, they did not have to apply many of the employability skills that the food chemistry module aimed to develop. Another student put this down to the short duration of the placement (12 weeks):

I was shown things, but not given anything to do that I could mess up that 
badly. If the placement was longer, and we were treated like an employee I think I would have needed the skills from the chemistry lab all the time.

The latter comment perhaps explains the result that students do consider the Food Chemistry modules have better prepared them for their future career, compared to traditional labs.

\subsection{Current improvements}

In the most recent iteration of this laboratory model, a project Wiki has been introduced. A Group page has been established for each group, and linking from this, pages to host their prepractical presentations, background literature, student laboratory manual document, and chemical risk assessment document. The purpose of this Wiki is to help the students to organise their work, to allow students outside the group to prepare for the laboratory ahead of the session by reading the manual and the risk assessment. It will also allow the tutor to review the resources more easily, both to determine suitability and to provide effective and timely feedback. This Wiki may also provide a useful tool for students to reflect on, record and share the feedback they receive during face-to-face feedback sessions. The use of the Wiki will be evaluated following the current academic session.

\section{Conclusion and Future}

The aims of this project were broadly met, with the successful implementation of an alternative laboratory practical for a group of third-year BSc Nutraceuticals students. The main objectives were to bridge the gap between the skills gained from traditional laboratories, and those required for the more independent final-year research project; to incorporate innovative approaches to feedback; and to integrate key employability skills into the curriculum. These were achieved through an iterative approach, building the skills required to ultimately allow students working in groups to research, design and run a laboratory for their class. The feedback has been particularly well received, and there is evidence that it will be reusable and will 'feed-forward' to other modules. The introduction of CATME rating surveys has provided an easier to manage, and more rigorous peer evaluation. Feedback from students who have completed their final year research projects was broadly in agreement that a variety of transferable skills have been developed, although creativity and critical analysis of the literature are considered less well developed than other skills through the model. Finally, the recent introduction of a project Wiki to help manage the organisation and communication within the groups, and with the tutor, will be evaluated.

\section{Acknowledgements}

The author thankfully acknowledges the help of Dr Barry Ryan, School of Food Science and Environmental Health, DIT and Dr Claire McDonnell, School of Chemistry, DIT. The support and funding from the DIT Learning Teaching and Technology centre (LTTC) and the DIT Teaching Scholarship scheme is also gratefully appreciated. Additionally, the author acknowledges the helpful comments and suggestions from the two anonymous peer reviewers.

\section{References}

Bennett, S. W. \& O'Neale, K. (1999). Progressive development of practical skills in chemistry: a guide to early-undergraduate experimental work. Royal Society of Chemistry.

Bennett, S. W., Seery, M. K., \& SovegjartoWigbers, D. (2009). Practical work in higher level chemistry education. Innovative methods in teaching and learning chemistry in higher education. Cambridge: RSC Publishing, 85-101. I. Eilks and B. Byers (Eds.)

Bennett, S. \& Overton, T. (2010). Evidentiallybased curriculum development introduction. Chemistry Education Research and Practice, 11(2), 73. doi:10.1039/C005348C

Black, P. \& Wiliam, D. (1998). Assessment and classroom learning. Assessment in education, 5(1), 7-74. 
Carnduff, J. \& Reid, N. (2003). Enhancing Undergraduate Chemistry Laboratories: prelaboratory and post-laboratory exercises. Royal Society of Chemistry, ISBN 0-85404378-0.

Carvalho, A. A. A., Aguiar, C., \& Maciel, R. (2009). A taxonomy of podcasts and its application to higher education. Retrieved from http: / / repository.alt.ac.uk/638/1/ ALT - C_09_proceedings_090806_web_0161 . pdf

Domin, D. S. (1999). A review of laboratory instruction styles. Journal of Chemical Education, 76(4), 543-547.

Durbridge, N. (1984). Media in course design, no. 9 , audio cassettes. The role of technology in distance education, 99-108.

Eilks, I., Markic, S., Baumer, M., \& Schanze, S. (2009). Cooperative learning in higher level chemistry education. Innovative Methods of Teaching and Learning Chemistry in Higher Education, Eds. Eilks, I \& Byers, B, 103-122.

Fleming, N. D. \& Mills, C. (1992). Not another inventory, rather a catalyst for reflection. to improve the academy. 11, 137-155.

Hattie, J. \& Timperley, H. (2007). The power of feedback. Review of Educational Research, 77(1), 81-112. doi:10 . 3102/ 003465430298487

Higgins, R., Hartley, P., \& Skelton, A. (2001). Getting the message across: the problem of communicating assessment feedback. Teaching in higher education, 6(2), 269-274.

Hrivnak, G. (2013). Catme smarter teamwork. Academy of Management Learning \& Education, 12(4), 679-681. Retrieved from www.CATME.org

Lunt, T. \& Curran, J. (2010). 'are you listening please?' the advantages of electronic audio feedback compared to written feedback. Assessment \& Evaluation in Higher Education, 35(7), 759-769. doi:10.1080/ 02602930902977772

Martin Davies, W. (2008). 'Not quite right': helping students to make better arguments. Teaching in Higher Education, 13(3), 327340 .
Mc Donnell, C., O'Connor, C., \& Seery, M. K. (2007). Developing practical chemistry skills by means of student-driven problem based learning mini-projects. Chemistry Education Research and Practice, 8(2), 130-139.

Nicol, D. (2010). The foundation for graduate attributes: developing self-regulation through self and peer assessment. The Quality Assurance Agency for Higher Education. Scotland.

Nicol, D. \& Macfarlane-Dick, D. (2004). Rethinking formative assessment in he: a theoretical model and seven principles of good feedback practice. C. Juwah, D. Macfarlane-Dick, B. Matthew, D. Nicol, D. ES Smith, B.(2004) Enhancing student learning though effective formative feedback, York, The Higher Education Academy.

Ohland, M. W., Loughry, M. L., Woehr, D. J., Bullard, L. G., Finelli, C. J., Layton, R. A., ... Schmucker, D. G. (2012). The comprehensive assessment of team member effectiveness: development of a behaviorally anchored rating scale for self- and peer evaluation. Academy of Management Learning \& Education, 11(4), 609-630. doi:10.5465/ amle.2010.0177

Overton, T., Johnson, S., \& Scott, J. (2011). Study and communication skills for the chemical sciences. Oxford University Press.

Pegg, A., Waldock, J., Hendy-Isaac, S., \& Lawton, R. (2012). Pedagogy for Employability, Higher Education Academy, York. Retrieved from https:// www . heacademy . ac . uk / sites / default / files / pedagogy_for_ employability_update_2012.pdf

Petty, G. (2006). Evidence based teaching. Cheltenham: Nelson Thornes, 42.

Taylor, P. C. \& Geden, J. V. (2008). Physical Sciences Discipline Project Enhancement Themes: Research-Teaching Linkages: Enhancing Graduate Attributes (S. Reinvented Labs in Bates, M. Aliotta, B. Sinclair, \& A. Kohnle, Eds.). Physical Sciences Discipline Project. Retrieved from http: / / www . enhancementthemes.ac.uk/ docs / publications / enhancing - graduateattributes-physical-sciences.pdf?sfvrsn $=24$ 
Yorke, M. \& Team, E. S. E. C.-o. (2004). Employability in Higher Education: What it is - What it is Not. LTSN Generic Centre. Retrieved from http://www.heacademy. ac. uk / resources / detail / employability / employability 336 


\section{Appendix I}

\section{Laboratory Report Self-Evaluation Check List}

Please ensure you have checked each of the following points below before you submit your report. Submissions will not be accepted without the completed check list. For group submissions, all group members must sign the check list form to confirm that they have, individually, read the final document.

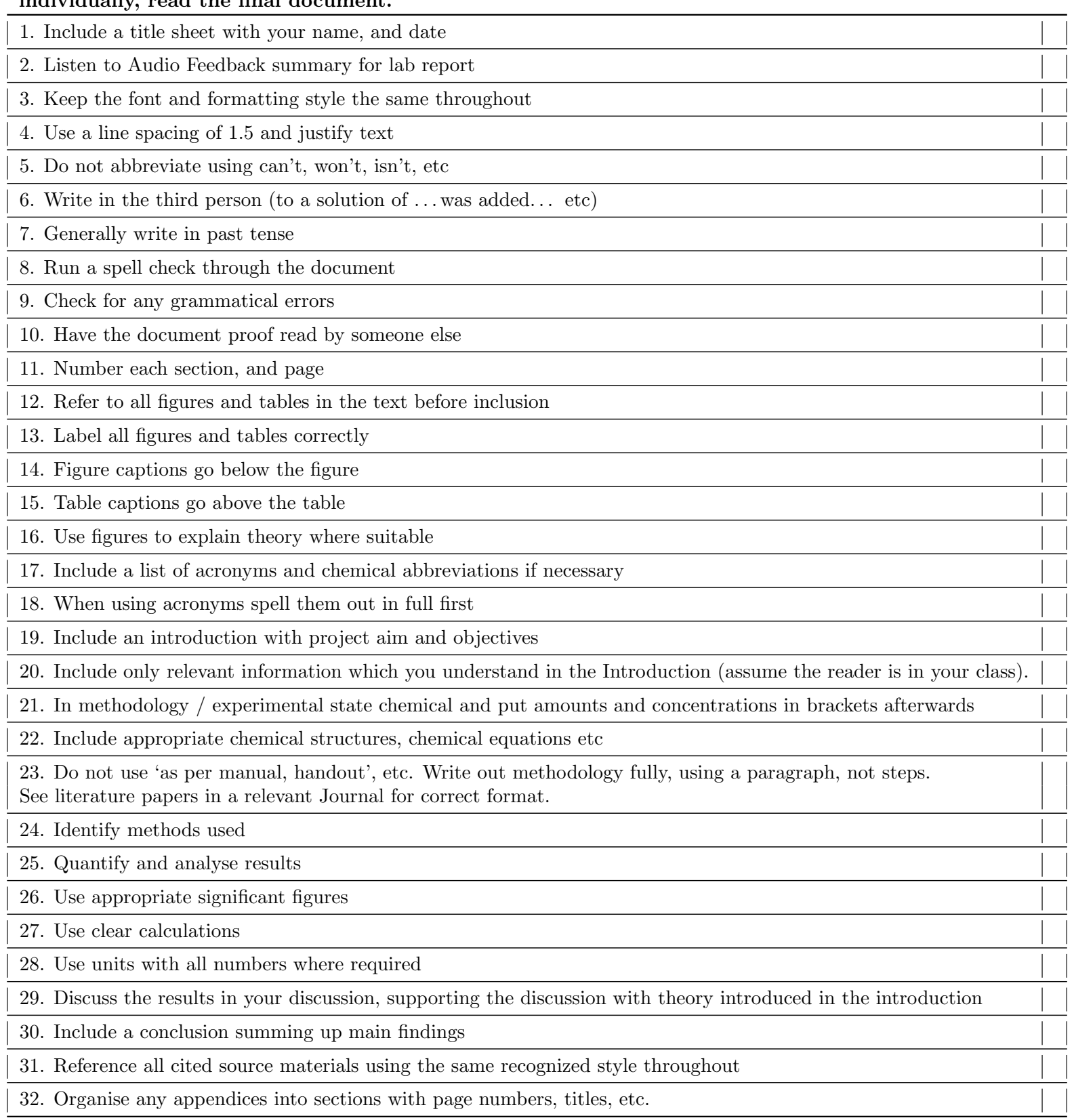

Student Signature

Module Code 